\title{
Anatomia de raízes de Actinocephalus (Koern.) Sano (Eriocaulaceae)
}

\author{
Vera Lucia Scatena ${ }^{1,3}$, Aline Oriani ${ }^{1}$ e Paulo Takeo Sano ${ }^{2}$
}

Recebido em 17/08/2004. Aceito em 05/05/2005

\begin{abstract}
RESUMO - (Anatomia de raízes de Actinocephalus (Koern.) Sano (Eriocaulaceae)). Estudou-se a anatomia de raízes de 27 espécimes de 13 espécies de Actinocephalus (Koern.) Sano que ocorrem nos campos rupestres brasileiros. As raízes de todos os espécimes estudados caracterizam-se por apresentar: epiderme unisseriada, com pêlos radiculares em grupos ou isolados; córtex com células isodiamétricas, com exceção daquelas localizadas mais internamente, que são menores e apresentam paredes espessadas; endoderme unisseriada, com células de paredes pouco ou totalmente espessadas, alongadas no sentido radial; periciclo formado por uma camada de células de paredes finas ou espessadas e cilindro vascular com elementos do metaxilema ocupando a posição central. A presença de córtex constituído por células isodiamétricas, sem aerênquima; epiderme e parênquima cortical com protuberâncias intracelulares associadas com fungos; são características consistentes para o gênero e corroboram a sua recente circunscrição. As raízes apresentam estruturas anatômicas semelhantes àquelas das espécies de Eriocaulaceae que ocorrem em solos secos, apesar de muitos indivíduos ocorrerem em solos úmidos, próximos a riachos.
\end{abstract}

Palavras-chave : raiz, Actinocephalus, novo gênero, monocotiledôneas

\begin{abstract}
Root anatomy of Actinocephalus (Koern.) Sano (Eriocaulaceae)). Root anatomy of 27 specimens of 13 species of Actinocephalus (Koern.) Sano were studied. All species occur in Brazilian rupestrian fields. All species present roots with uniseriate epidermis, isolated or agregated root hairs; isodiametric cortical cells, except in the innermost layers that are smaller and present thickened wall cells; uniseriate radially elongated endodermis, with parcial or totally thickened wall cells; uniseriate pericycle, with thin or thickened wall cells; and vascular cylinder with metaxylem in central position. Cortex with isodiametric cells, without aerenchyma; epidermis and cortical parenchyma with intracellular protuberances associated with fungi; are consistent to the recent genus circunscription. Althouth a lot of species are also known for growing in damp habitats, near to small rivers, their roots present anatomical features similar to that Eriocaulaceae species that occur in dry soils.
\end{abstract}

Kew words: root, Actinocephalus, new genus, monocotyledons

\section{Introdução}

Os campos rupestres são considerados um dos maiores centros de biodiversidade e endemismos do país (Harley 1995) e a fisionomia da vegetação decorre, em geral, de características edafo-climáticas marcadamente adversas, como temperaturas extremas, solos rochosos, ácidos, pobre em nutrientes e com baixa capacidade de retenção de água, além das altas taxas de radiação solar e ventos fortes (Warming 1892).

Essa formação vegetal domina a paisagem acima de $1.000 \mathrm{~m}$ de altitude, no Brasil Central; apresenta estrato herbáceo contínuo, onde as Eriocaulaceae são amplamente distribuídas e esparsos arbustos e subarbustos (Giulietti \& Pirani 1988).
Dentre os gêneros com maior número de espécies destacam-se Eriocaulon L., Paepalanthus Mart. e Syngonanthus Ruhland (Moldenke 1971). Paepalanthus é o maior gênero da família, tendo sido apontado como polifilético em análise cladística (Giulietti et al. 2000). Com esse resultado concluiu-se que o gênero deve ser separado em vários grupos monofiléticos menores, para que possa refletir, com propriedade, a história evolutiva do grupo. Sano (2004), com base em dados morfológicos e biológicos de Paepalanthus sect. Actinocephalus (Koern.) Ruhland, e ainda, utilizando informações sobre fitoquímica e citotaxonomia, propõe a elevação desta seção à categoria genérica de Actinocephalus (Koern.) Sano.

Estudos anatômicos com raízes de espécies de Paepalanthus foram desenvolvidos por Poulsen

\footnotetext{
1 Universidade Estadual Paulista, Instituto de Biociências, Departamento de Botânica, C. Postal 199, CEP 13506-900, Rio Claro, São Paulo, Brasil. Bolsas CNPq e FAPESP.

2 Universidade de São Paulo, Instituto de Biociências, Departamento de Botânica, C. Postal 11461, CEP 05422-970, São Paulo, São Paulo, Brasil

3 Autor para correspondência: vscatena@rc.unesp.br
} 
(1888), Ruhland (1903), Malmanche (1919), Tomlinson (1969), Hensold (1988), Stützel (1988), Scatena \& Moraes (1996), Scatena \& Barros (1996), Scatena \& Rosa (2001), Coan et al. (2002) e Scatena et al. (2005). Na maioria destes trabalhos, os autores relacionam a presença de determinadas estruturas anatômicas com o ambiente e com a taxonomia do grupo.

Diferentes autores, como Poulsen (1888), Holm (1901), Malmanche (1919), Tomlinson (1969), Stützel (1988) e Scatena et al. (2005), consideram que existem dois tipos básicos de raízes nos diferentes gêneros de Eriocaulaceae: um deles com parênquima cortical formado por diafragmas e o outro com o parênquima cortical sem essa característica. De acordo com Scatena et al. (2005) o segundo tipo descrito por estes autores ocorre em representantes de Blastocaulon Ruhland, Philodice Mart., Tonina Aubl. e Actinocephalus (Koern.) Sano.

Considerando a importância de Actinocephalus (Koern.) Sano para as Eriocaulaceae, o objetivo deste trabalho é informar as características anatômicas das raízes de suas espécies, associando-as ao ambiente, visando corroborar a classificação taxonômica proposta por Sano (2004).

\section{Material e métodos}

O estudo anatômico das raízes de Actinocephalus foi realizado a partir de exsicatas do Herbário do Departamento de Botânica da Universidade de São Paulo (SPF), provenientes de diferentes localidades do Brasil. Utilizou-se também material coletado em diferentes municípios de Minas Gerais, Brasil, cujas exsicatas estão depositadas no Herbário do Instituto de Biociências da Universidade Estadual Paulista, Campus de Rio Claro (HRCB). As espécies estudadas estão detalhadas na Tab. 1.

As raízes do material de herbário foram fervidas em água com glicerina para expansão dos tecidos e estocadas em álcool 70\%. Do material coletado, parte foi herborizada para posterior identificação e parte foi fixada em FAA 50 (Johansen 1940), sendo posteriormente transferida para álcool $70 \%$, com

Tabela 1. Espécies de Actinocephalus (Koern.) Sano e coleções utilizadas no estudo anatômico.

\begin{tabular}{|c|c|c|}
\hline Espécie & Localidade & Coleção \\
\hline Actinocephalus bongardii (A. St.-Hil.) Sano & $\begin{array}{l}\text { MG - Santana do Riacho } \\
\text { MG - Santana do Riacho }\end{array}$ & $\begin{array}{l}\text { Scatena } \text { et al. } 257-12 / \mathrm{V} / 2003 \\
\text { Scatena } \text { et al. } 258-12 / \mathrm{V} / 2003\end{array}$ \\
\hline Actinocephalus brachypus (Bong.) Sano & $\begin{array}{l}\text { MG - Diamantina } \\
\text { MG - Diamantina } \\
\text { MG - Diamantina }\end{array}$ & $\begin{array}{l}\text { Giulietti } \text { et al. CFCR } 2334 \text { - 30/X/1981 } \\
\text { Stützel } \text { et al. } 30 \text { - } 25 / \mathrm{II} / 1987 \\
\text { Pirani } \text { et al. CFCR } 11802-10 / \mathrm{I} / 1988\end{array}$ \\
\hline Actinocephalus cabralensis (Silveira) Sano & MG - Augusto de Lima & Sano et al. CFCR 15292 - 20/III/1994 \\
\hline Actinocephalus ciliatus (Bong.) Sano & $\begin{array}{l}\text { MG - Serro } \\
\text { MG - Diamantina }\end{array}$ & $\begin{array}{l}\text { Sano et al. } 808-10 / \mathrm{II} / 1998 \\
\text { Sano et al. } 850-12 / \mathrm{II} / 1998\end{array}$ \\
\hline Actinocephalus claussenianus (Koern.) Sano & MG - São Roque de Minas & Sano 1000 - 20/III/1998 \\
\hline Actinocephalus denudatus (Koern.) Sano & $\begin{array}{l}\text { MG - Grão-Mogol } \\
\text { BA - Piatã }\end{array}$ & $\begin{array}{l}\text { Pirani et al. } 4346-9 / \mathrm{V} / 1979 \\
\text { Ganev } 1634-6 / \mathrm{XII} / 1992\end{array}$ \\
\hline Actinocephalus falcifolius (Koern.) Sano & $\begin{array}{l}\text { MG - Lavras Novas } \\
\text { MG - Ouro Preto }\end{array}$ & $\begin{array}{l}\text { Giulietti } \text { et al. CFCR } 9196 \text { - 25/I/1986 } \\
\text { Roque \& Souza } 340 \text { - 7/VIII/1997 }\end{array}$ \\
\hline Actinocephalus herzogii (Moldenke) Sano & BA - Piatã & Ganev $1711-20 / X I I / 1992$ \\
\hline Actinocephalus polyanthus var. bifrons (Silveira) Sano & MG - Diamantina & Scatena et al. $248-1 / \mathrm{II} / 2002$ \\
\hline Actinocephalus polyanthus var. polyanthus (Bong.) Sano & $\begin{array}{l}\text { MG - Santana do Riacho } \\
\text { MG - Santana do Riacho } \\
\text { MG - Santana do Riacho }\end{array}$ & $\begin{array}{l}\text { Sano CFSC } 13029-19 / \mathrm{II} / 1993 \\
\text { Scatena et al. } 254-11 / \mathrm{V} / 2003 \\
\text { Scatena } \text { et al. } 259-12 / \mathrm{V} / 2003\end{array}$ \\
\hline Actinocephalus ramosus (Wikstr.) Sano & $\begin{array}{l}\text { MG - Itambé do Mato Dentro } \\
\text { BA - Piatã }\end{array}$ & $\begin{array}{l}\text { Hensold } 427 \text { CFCR } 3676 \text { - 13/I/1982 } \\
\text { Sano et al. CFCR } 14673 \text { - 1/III/1994 }\end{array}$ \\
\hline Actinocephalus rigidus (Bong.) Sano & $\begin{array}{l}\text { MG - Diamantina } \\
\text { MG - Diamantina }\end{array}$ & $\begin{array}{l}\text { Giulietti } \text { et al. CFCR } 1873 \text { - 30/VIII/1981 } \\
\text { Sano et al. } 691 \text { - 8/XII/1997 }\end{array}$ \\
\hline Actinocephalus robustus (Silveira) Sano & $\begin{array}{l}\text { MG - Santana do Riacho } \\
\text { MG - São Roque de Minas }\end{array}$ & $\begin{array}{l}\text { Semir \& Joly CFSC } 3760 \text { - 6/I/1973 } \\
\text { Costa } 120 \text { - 2/X/1999 }\end{array}$ \\
\hline Actinocephalus stereophyllus (Ruhland) Sano & $\begin{array}{l}\text { MG - Diamantina } \\
\text { MG - Diamantina } \\
\text { MG - Diamantina }\end{array}$ & $\begin{array}{l}\text { Menezes et al. CFCR 141- 18/VII/1980 } \\
\text { Sano et al. } 705 \text { - 8/XII/1997 } \\
\text { Sano } \text { et al. } 735 \text { - 9/XII/1997 }\end{array}$ \\
\hline
\end{tabular}

CFCR = Coleção Flora dos Campos Rupestres; CFSC = Coleção Flora da Serra do Cipó. 
algumas gotas de glicerina, para a realização dos estudos anatômicos.

As secções anatômicas foram feitas à mão livre, com lâminas de barbear, na região mediana das raízes, e submetidas ao processo de dupla coloração com fucsina e azul de astra (Roeser 1962), sendo montadas em lâminas semipermanentes.

\section{Resultados}

As secções transversais mostram que todas as raízes estudadas apresentam o mesmo padrão anatômico, com epiderme, córtex e cilindro vascular (Fig. 1-10).

Em todas as espécies a epiderme (E) é unisseriada, com células de paredes delgadas, que apresentam forma irregular (Fig. 8), ou forma arredondada (Fig. 2, 10).

As células epidérmicas apresentam pêlos radiculares mais comumente em grupos (Fig. 4, 8-10) e, às vezes, isolados (Fig. 2). Partículas de areia são encontradas aderidas aos mesmos, como pode ser observado em Actinocephalus brachypus (Fig. 5).

O parênquima cortical apresenta três a cinco camadas de células aproximadamente isodiamétricas, com parede periclinal interna levemente mais espessada do que a externa nas espécies Actinocephalus brachypus (Fig. 1, 5) e Actinocephalus rigidus (Fig. 7, 10). Os espaços intercelulares são relativamente pequenos (Fig. 1-10). Uma ou duas das camadas corticais mais internas, próximas à endoderme, apresentam células menores e com paredes mais espessadas, onde a parede periclinal interna é mais espessada do que a externa (Fig. 1, 3-5, 7-10) ou, menos freqüentemente, o espessamento é homogêneo (Fig. 2, 6). Em Actinocephalus rigidus as células da camada cortical interna apresentam conteúdo não identificado (Fig. 7 - cabeças de seta).

Nas raízes de todas as espécies foram observadas protuberâncias intracelulares, tanto na epiderme, como no parênquima cortical, como pode ser observado em Actinocephalus herzogii (Fig. 8 - setas).

Em todas as espécies estudadas a endoderme (EN) é unisseriada e constituída por células de paredes espessadas e alongadas no sentido radial (Fig. 1-10). O espessamento das paredes pode ser pouco acentuado (Fig. 2, 4, 6) ou muito acentuado (Fig. 1, 3, 5, 7-10). Ao seccionar-se raízes mais velhas e mais novas de um mesmo espécime, como em Actinocephalus denudatus (Fig. 3-4, respectivamente), observa-se que, tanto nas células da endoderme como nas células das camadas mais internas do parênquima cortical, o espessamento varia com a idade. As células da endoderme destacam-se das demais pela diferença de coloração das paredes.

$\mathrm{O}$ periciclo $(\mathrm{P})$ é unisseriado na grande maioria das espécies, com exceção de Actinocephalus claussenianus, e suas células podem apresentar paredes espessadas (Fig. 1, 7) ou delgadas (Fig. 2-6, 8-10). Nas espécies com células de paredes espessadas, o espessamento é uniforme (Fig. 1) ou desigual (Fig. 7). Nas espécies Actinocephalus brachypus (Fig. 1), Actinocephalus bongardii (Fig. 2) e Actinocephalus polyanthus var. polyanthus (Fig. 6) o periciclo não é contínuo e pode-se observar o protoxilema contíguo à endoderme.

O cilindro vascular contém um a vários elementos de metaxilema ocupando a posição central (Fig. 1-3, 6-7, 9). Os elementos do floema são reduzidos, ocupam a posição periférica e intercalam-se com os pólos de protoxilema (Fig. 1-10).

Todas as espécies estudadas apresentam raízes laterais, como pode-se observar em Actinocephalus cabralensis (Fig. 9), e associações com fungos, como pode ser observado em Actinocephalus rigidus (Fig. 10 - asteriscos).

\section{Discussão}

Num estudo anatômico dos órgãos vegetativos de diferentes gêneros de Eriocaulaceae brasileiras, Scatena et al. (2005) reafirmaram a presença de dois tipos básicos de raízes na família, como já havia sido elucidado por Poulsen (1888), Holm (1901), Malmanche (1919), Tomlinson (1969) e Stützel (1988). No primeiro tipo incluem-se aquelas esponjosas, esbranquiçadas, com exoderme distinta e células corticais braciformes de paredes levemente espessadas. No segundo tipo incluem-se aquelas finas, marrons, com células isodiamétricas no córtex, portanto que não apresentam aerênquima, e que ocorrem principalmente em espécies de Blastocaulon e Actinocephalus.

As raízes das espécies de Actinocephalus estudadas neste trabalho são finas, de coloração marrom e sua estrutura anatômica é compatível com o segundo tipo descrito por Scatena et al. (2005), corroborando os seus resultados. As raízes estudadas assemelham-se a de Syngonanthus aurifibratus Silveira, Syngonanthus elegans Ruhland e Syngonanthus lineares Ruhland (citada como Syngonanthus imbricatus Ruhland) - espécies de 


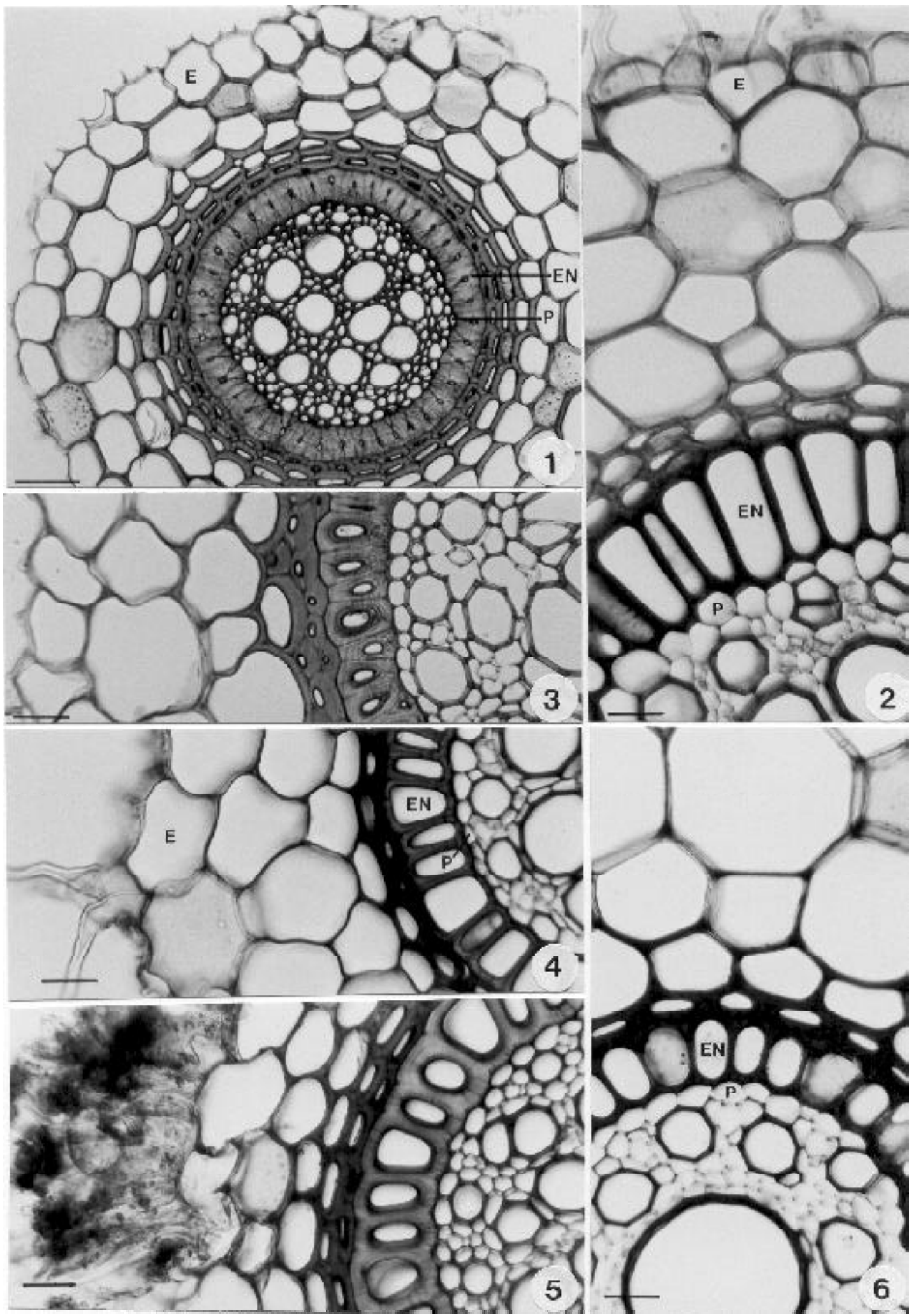

Figuras 1-6. Secções transversais da região mediana de raízes de Actinocephalus (Koern.) Sano. 1. Actinocephalus brachypus (Bong.) Sano (CFCR 2334). 2. Actinocephalus bongardii (A. St.-Hil.) Sano (Scatena et al. 258). 3-4. Actinocephalus denudatus (Koern.) Sano (Ganev 1634). 5. Actinocephalus brachypus (Bong.) Sano (CFCR 11802). 6. Actinocephalus polyanthus var. polyanthus (Bong.) Sano

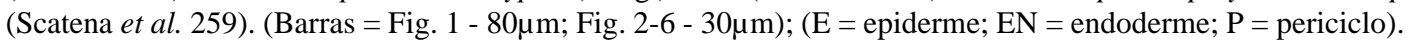




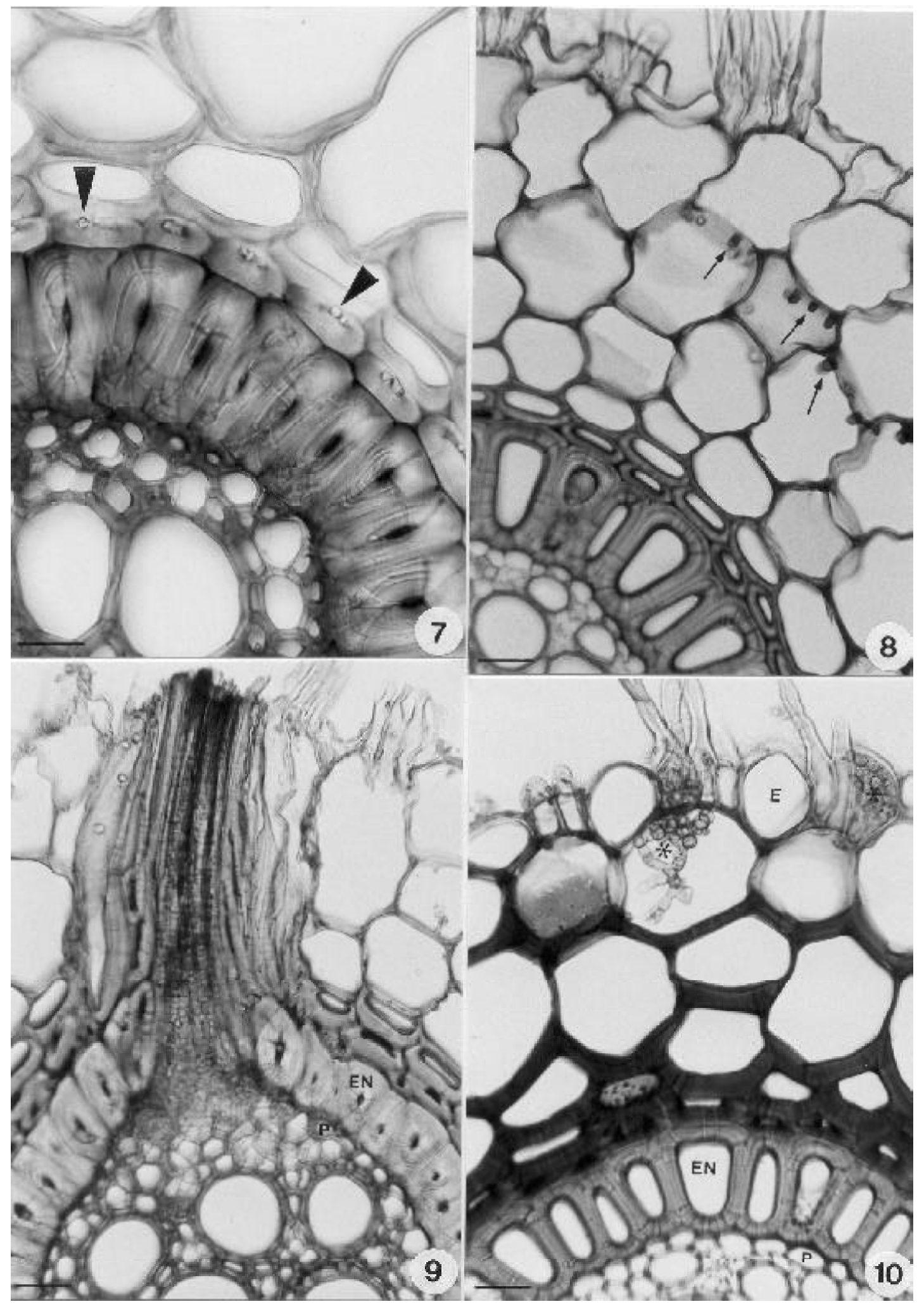

Figuras 7-10. Secções transversais da região mediana de raízes de Actinocephalus (Koern.) Sano. 7. Actinocephalus rigidus (Bong.) Sano (CFCR 1873). 8. Actinocephalus herzogii (Moldenke) Sano (Ganev 1711). 9. Actinocephalus cabralensis (Silveira) Sano (CFCR 15292).

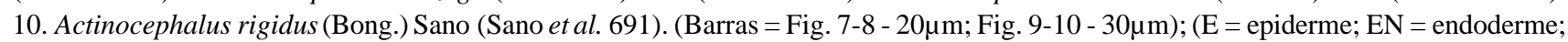
$\mathrm{P}=$ periciclo; setas $=$ projeções das paredes; cabeças de seta $=$ conteúdo celular; asteriscos $=$ fungos $)$. 
Syngonanthus Ruhland estudadas por Scatena \& Menezes (1996) - a Paepalanthus vellozioides Koern., Paepalanthus latipes Silveira, Paepalanthus pauciflorus Koern. e Paepalanthus planifolius Koern. - espécies de Paepalanthus subg.Platycaulon estudadas por Scatena \& Moraes (1996) - e a Blastocaulon albidum Ruhland, Blastocaulon prostratum Ruhland e Blastocaulon scirpeum (Mart.) A.M. Giulietti (Mart.) - espécies de Blastocaulon Ruhland estudadas por Scatena et al. (1999). São também semelhantes a Paepalanthus applanatus Ruhland, Paepalanthus geniculatus Kunth e Paepalanthus macrocephalus Koern., pertencentes a Paepalanthus subsect. Aphorocaulon, estudadas por Scatena \& Rosa (2001), em que as raízes são relativamente finas e as células do parênquima cortical são isodiamétricas, sem grandes espaços intercelulares.

Todas as espécies citadas acima crescem em solos que permanecem secos na maior parte do ano e a presença de parênquima cortical sem aerênquima está relacionada a este tipo de ambiente segundo os diferentes autores que as estudaram. Segundo Stützel (1988) as espécies que apresentam o parênquima cortical com diafragmas (aerênquima) são aquelas que crescem em solos encharcados.

Embora a grande maioria das espécies de Actinocephalus estudadas ocorra associada a linhas de drenagem ou a pequenos vales com solo úmido e encharcado (em alguns meses do ano), elas apresentam estruturas anatômicas de raízes semelhantes àquelas Eriocaulaceae que crescem em solos secos. Uma possível interpretação do que ocorre é que, apesar de os indivíduos das espécies estarem associados a linhas de drenagem, os solos não se apresentam encharcados a maior parte do ano. $\mathrm{O}$ solo fica completamente seco de maio a setembro, úmido em abril e outubro e encharcado apenas durante quatro meses, de novembro a fevereiro.

A endoderme foi determinada pela diferença de coloração, que é devida à impregnação de lignina e de suberina nas paredes das células que a constituem, e também, pela observação do ponto de origem das raízes laterais, que é no periciclo, situado imediatamente adjacente à endoderme. A nomenclatura adotada neste trabalho foi confirmada pela microscopia eletrônica de transmissão (dados dos autores ainda não publicados), e é semelhante à interpretação de Poulsen (1888), Holm (1901), Ruhland (1903), Malmanche (1919), Tomlinson (1969) e Stützel (1988).

A presença de epiderme unisseriada constituída por células de paredes finas e pêlos radiculares em grupos ou isolados é verificada em todas as espécies de Eriocaulaceae já estudadas (Poulsen 1888; Holm 1901; Ruhland 1903; Malmanche 1919; Tomlinson 1969; Stuitzel 1988; Scatena \& Rocha 1995; Scatena \& Barros 1996; Scatena \& Menezes 1996; Scatena \& Moraes 1996; Scatena et al. 1999; Scatena \& Rosa 2001; Coan et al. 2002; Scatena et al. 2005).

Nas raízes de Actinocephalus os pêlos radiculares são numerosos e muitas partículas de areia do solo se aderem a eles, resultando em um aparente aumento da espessura da raiz. Esta característica é importante, pois aumenta a superfície de contato da raiz, o que pode corresponder a uma adaptação fisiológica da planta a fatores do solo, como $\mathrm{pH}$, disponibilidade de nutrientes, ou uma interação desses fatores.

Também deve ser considerado que, nas raízes de Actinocephalus, a aderência de partículas do solo em toda sua extensão pode estar relacionada com a possível produção de mucilagem pelas células da epiderme, como ocorre em espécies de Syngonanthus (Scatena \& Menezes 1996). As autoras salientam que esta secreção protege a raiz contra a dessecação, entre outras funções.

Conforme foi observado nos resultados, todas as espécies estudadas neste trabalho apresentam associações com fungos, que penetram nas raízes principalmente através dos pêlos radiculares e chegam até as células do córtex. Sabe-se que é comum a presença de fungos nas raízes de Eriocaulaceae dos campos rupestres brasileiros. Tais fungos absorvem os nutrientes lixiviados pelas águas da chuva, da neblina e do orvalho, disponibilizando-os à planta (Hughes 1976) e provavelmente atuam na permeabilidade das células das raízes, com as quais formam associações do tipo micorrízicas.

As raízes das espécies de Actinocephalus estudadas também apresentam epiderme e parênquima cortical com protuberâncias intracelulares, conforme foi ilustrado paraActinocephalus herzogii. Acredita-se que essas protuberâncias se formam envolvendo as hifas fúngicas, o que mais uma vez leva ao aumento da superfície de contato da raiz, facilitando o aporte de água e nutrientes.

Nos resultados aqui apresentados todas as espécies de Actinocephalus são anatomicamente semelhantes entre si, o que corrobora a homogeneidade do grupo já destacada por Sano ao propor o novo gênero (Sano 2004). Enquanto as demais espécies de Paepalanthus podem apresentar aerênquima no córtex, ou córtex constituído por células isodiamétricas, em Actinocephalus a ausência de aerênquima, em 
todas as espécies estudadas, bem como a presença de epiderme e parênquima cortical com protuberâncias intracelulares associadas com fungos são características consistentes para separar o gênero e corroboram a sua recente circunscrição.

\section{Referências bibliográficas}

Coan, A.I.; Scatena, V.L. \& Giulietti, A.M. 2002. Anatomia de algumas espécies aquáticas de Eriocaulaceae brasileiras. Acta Botanica Brasilica 16(4): 371-384.

Giulietti, A.M. \& Pirani, J.R. 1988. Patterns of geographic distribution of some plant species from the Espinhaço Range, Minas Gerais and Bahia, Brazil. Pp. 39-69. In: P.E. Vanzolini \& W.R. Heyer (eds.). Proceedings of a workshop of neotropical distribution patterns . Rio de Janeiro, Academia Brasileira de Ciências.

Giulietti, A.M.; Scatena, V.L.; Sano, P.T.; Parra, L.; Queiroz, L.P.; Harley, R.M.; Menezes, N.L.; Ysepon, A.M.B.; Salatino, A.; Salatino, M.L.; Vilegas, W.; Santos, L.C.; Ricci, C.V.; Bonfim, M.C.P. \& Miranda, E.B. 2000. Multidisciplinary studies on neotropical Eriocaulaceae. In: K.L. Wilson \& D. Morrison (eds.). Monocots: Systematics and evolution. Collingwood, CSIRO Publishing.

Harley, R.M. 1995. Flora of the Pico das Almas - Chapada Diamantina, Bahia, Brazil. In: B. Stannard (ed.). Kew, Royal Botanic Gardens.

Hensold, N. 1988. Morphology and systematics of Paepalanthus subgenus Xeractis (Eriocaulaceae). Systematic Botany Monographs. Michigan, The American Society of Plants Taxonomists.

Holm, T. 1901. Eriocaulondecangulare L. An anatomical study. Botanical Gazette 31: 17-39.

Hughes, S.J. 1976. Sooty moulds. Mycologia 68: 693-820.

Johansen, D.A. 1940. Plant microthechnique. New York, Mc Graw-Hill Book Co.

Malmanche, L.A. 1919. Contribution à l'étude anatomique des Eriocaulacées et des families voisines: Restiacées, Centrolepidacées, Xyridacées, Philydracées, Mayacacées. Thesis. Saint Cloud, Paris.

Moldenke, H.N. 1971. A fifth summary of the Verbenaceae, Avicenniaceae, Stilbaceae, Dicrastylidaceae, Symphoremaceae, Nyctanthaceae and Eriocaulaceae of the world as to valid taxa, geographic distribution and synonymy. Michigan, Annals of the Arboretum: Braun - Brumfield
Poulsen, V.A. 1888. Anatomiske studien over Eriocaulaceerne Vidensk. Meddr. Dansk Naturhistorisk. Foren 4(10): 221-386.

Roeser, K.R. 1962. Die Nadel der SchwarzkieferMassenprodukt und Kunstwert der Natur. Mikrokosmos 61: 33-36.

Ruhland, W. 1903. Eriocaulaceae. In: A. Engler (ed.). Das Pflazenreich 4(30): 1-294. Leipzig, Wilhelm Engelmann.

Sano, P.T. 2004.Actinocephalus (Körn.) Sano (Paepalanthus sect. Actinocephalus), a new genus of Eriocaulaceae, and other taxonomic and nomenclatural changes involving Paepalanthus Mart. Taxon 53(1): 99-107.

Scatena, V.L. \& Rocha, C.L.M. 1995. Anatomia dos órgãos vegetativos e do escapo floral de Leiothrix crassifolia (Bong.) Ruhl. Eriocaulaceae, da Serra do Cipó - M.G. Acta Botanica Brasilica 9(2): 195-211.

Scatena, V.L. \& Barros, A.M. 1996. Aspectos morfoanatômicos de Paepalanthus hilairei Koern. (Eriocaulaceae) da Serra do Cipó, M.G. Arquivos de Biologia e Tecnologia 39(1): 75-88.

Scatena, V.L. \& Menezes, N.L. 1996. Anatomia de raízes de Syngonanthus Ruhl. (Eriocaulaceae). Revista Brasileira de Biologia 56(2): 333-343.

Scatena, V.L. \& Moraes, A.R.S. 1996. Anatomia de raízes, folhas e escapos de Paepalanthus subgênero Platycaulon (Eriocaulaceae) da Serra do Cipó - M.G. Arquivos de Biologia e Tecnologia 39(4): 1021-35.

Scatena, V.L.; Cardoso, V.A. \& Giulietti, A.M. 1999. Morfoanatomia de espécies de Blastocaulon Ruhland (Eriocaulaceae). Acta Botanica Brasilica 13: 29-41.

Scatena, V.L. \& Rosa, M.M. 2001. Morphology and anatomy of the vegetative organs and scapes from Aphorocaulon (Paepalanthus, Eriocaulaceae). Brazilian Archives of Biology and Tecnology 44(1): 49-58.

Scatena, V.L.; Giulietti, A.M.; Borba, E.L. \& Berg, C. van den. 2005. Anatomy of Brazilian Eriocaulaceae: correlation with taxonomy and habitat using multivariate analyses. Plant Systematics and Evolution 253: 1-22.

Stützel, T. 1988. Untersuchungen zur Wurzelanatomie der Eriocaulaceen. Flora 180: 223-239.

Tomlinson, P.B. 1969. Commelinales - Zingiberales. In: C.R. Metcalfe (ed.). Anatomy of the Monocotyledons III. Oxford, Clarendon Press.

Warming, E. 1892. Lagoa Santa, contribuição para a geografia fitobiológica. Pp. 1-284. In: E. Warming \& M.G. Ferri (eds.). 1973. Lagoa Santa e a vegetação dos cerrados brasileiros. Belo Horizonte, Itatiaia. 
